\title{
As fontes institucionais de informação agenda ambiental no Brasil e em Portugal: Estado, comunidade científica e entidades ecológicas
}

Antonio Teixeira de Barros*

\section{Resumo}

Estudo analítico sobre o papel político das fontes de informação no jornalismo ambiental no Brasil e em Portugal, no período de 1990 a 2010. A metodologia consiste na técnica de meta-análise ou revisão sistemática de bibliografia sobre o tema. $\mathrm{O}$ corpus da pesquisa compreende dez obras de referência na comunidade acadêmica (cinco de cada país), a fim de contemplar as principais obras que documentam e sintetizam a produção científica no período estudado. Conclui que as fontes de informação ambiental nos dois países seguem as mesmas tendências históricas e sociais, especialmente no que se refere às instituições governamentais, à comunidade científica e às organizações do terceiro setor.

\section{Palavras-chave}

Estudos ambientais. Fontes institucionais de informação. Brasil and Portugal.

\section{Abstract}

An analytical study regarding the political role of information sources for the environmental journalism in Brazil and in Portugal during the period of 1990 to 2000. The methodology consists in a meta-analysis technique or the systematic inspection of the bibliography regarding this theme. The research corpus conceives ten works of reference in the academic community (five of each country), in order to contemplate the main works which document and synthesize the scientific production of the studied period. I have concluded that the environmental sources of information in both countries have the same historic and social tendencies, especially when regarding the

\footnotetext{
* Antonio Teixeira de Barros é Doutor em Sociologia; e docente e pesquisador do Programa de Mestrado Profissional em Poder Legislativo do Centro de Formação da Câmara dos Deputados. E-mail: antonibarros@gmail.com.
} 
governmental institutions, the scientific community and the organizations of the third section.

\section{Keywords}

Environmental studies. Environmental politics. Brazil and Portugal.

\section{Introdução}

Há vários paralelos entre Brasil e Portugal no que se refere à formação dos movimentos em defesa do ambiente (BARROS; SOUSA, 2010). Essa constatação indica que as convergências também são extensivas aos paradigmas jornalísticos relacionados à cobertura de temas ecológicos nos dois países, especialmente no que se refere à abordagem sobre as fontes de informação (BARROS; SOUSA, 2010; BARROS, 2015a). Como demonstram esses autores, nos dois países, a formação de uma agenda verde ocorreu mediante a participação de fontes diretamente ligadas ao Estado, à comunidade científica e aos movimentos ambientais. Diante dessa constatação é que se justifica a abordagem aqui proposta, ou seja, uma análise comparativa com foco específico nas fontes de informação, sob a ótica dos estudos de jornalismo ambiental realizados no Brasil e em Portugal no período de 1990 a 2010. O objetivo é analisar, sob a perspectiva qualitativa, como os estudos de jornalismo realizados no Brasil e em Portugal nas últimas décadas abordam a relação entre jornalistas e fontes e que aspectos são enfatizados nas pesquisas realizadas sobre o tema nesse período nos dois países, em função das convergências mencionadas.

O problema de pesquisa é composto pelas seguintes questões: (a) Como as fontes de informação ambiental são abordadas pelos estudos de jornalismo e meio ambiente no Brasil e em Portugal no período examinado? (b) Qual o tratamento dispensado aos atores estatais que atuam como fontes de informação ambiental para a imprensa? (c) Como a comunidade científica é representada nesses estudos, sob a ótica de fontes informativas? (d) Qual o papel político das entidades ambientais como fornecedoras de informação para a imprensa? (e) Que relações são estabelecidas entre esses atores no âmbito das fontes informativas no campo ecológico sob a ótica da mediatização das informações ecológicas? 
O pressuposto sociológico que norteia o estudo é o de que o discurso da imprensa sobre ambiente não deve ser entendido como produção autônoma, uma vez que as notícias sobre o tema se reportam a diversos atores sociais (instituições estatais, partidos políticos, entidades científicas, movimentos sociais e ambientalistas) que atuam como fontes. Trata-se, pois, de um discurso condicionado por múltiplos fatores, segundo a perspectiva da teoria multifactorial da noticia (SOUSA, 2000; 2006). O jornalismo, como discurso social poroso e permeável, recebe influências de diversas vertentes do discurso ecológico, conforme o perfil e a natureza das fontes de informação.

$\mathrm{O}$ recorte analítico inclui as fontes fundadoras do discurso ambiental mediado pela imprensa, conforme identificado em pesquisa anterior (BARROS, 1999). São elas as fontes oficiais/governamentais, a comunidade científica e as organizações não governamentais. Esse interplay de atores, com suas diferentes perspectivas, interesses e enquadramentos, é considerado fundamental para a compreensão das dinâmicas de mediatização ambiental, entendida como a apropriação pela imprensa de discursos oriundos de outros campos (BARROS, 2013). Segundo o mesmo autor, a mediatização favoreceu a visibilidade da agenda verde, mediante a exposição dos argumentos e justificações dos diferentes atores envolvidos. Apesar de não serem os únicos atores, os agentes que representam o Estado, a comunidade científica e as entidades ecológicas são considerados pelo autor mencionado os protagonistas nesse processo de ampliação da visibilidade ambiental na arena midiática.

\section{Descrição da Pesquisa e da Metodologia}

A pesquisa se caracteriza como estudo de caso de natureza exploratória e qualitativa, com o auxílio da técnica de metanálise ou revisão sistemática, que consiste no exame minucioso de pesquisas já realizadas sobre um tema determinado, a fim de organizar o conhecimento produzido, comparar tendências, metodologias e produzir inferências (CLARKE, 2001). Nessa perspectiva, a metanálise foi aplicada com base na concepção operacional de obras-síntese, ou seja, publicações expressivas e representativas em termos de abordagens, abrangência temática, ferramentas metodológicas e referencial teórico utilizado. Foram selecionadas dez obras (cinco de cada país), de modo a incluir no corpus da pesquisa obras-síntese referentes às diversas 
fases do período histórico estudado ${ }^{1}$. O pressuposto, portanto, é que uma única obra-síntese pode servir de referência para a análise dos conteúdos de uma área de conhecimentos no decorrer de um período $\mathrm{X}$, como um decênio ou um quinquênio.

A opção pelos estudos de jornalismo como objeto de análise qualitativa se justifica pela amplitude analítica das publicações, que apresentam característica especial, ao proporcionar a edição de obra-síntese, ou seja, em uma única publicação é possível encontrar análises relativas à cobertura jornalística acerca da evolução de um tema, durante um longo período, além de análises comparativas e diacrônicas. A denominação obra-síntese se explica, portanto, pela capacidade de uma única publicação sintetizar estudos de jornalismo ambiental referentes a amplos recortes temáticos e históricos.

A respeito do corpus, cabe explicar ainda que a profusão de estudos sobre o tema é característica da década de 1990, impulsionados pela cobertura jornalística acerca da Cúpula da Terra (Rio 92) e depois com a divulgação dos relatórios do Painel Intergovernamental sobre Mudanças Climáticas (2003 a 2007). Tudo isso explica a concentração de publicações nas décadas de 1990 e 2010. Em levantamento realizado anteriormente, constatou-se que não há registro de estudos sobre jornalismo ambiental na década de 1970 nos dois países (BARROS; SOUSA, 2010). Nessa década, os estudos se limitaram ao campo das Ciências da Natureza e das Ciências Sociais. A partir da metade da década de 1980 é que as pesquisas sobre comunicação ambiental, e mais especificamente acerca do jornalismo ambiental, começaram a ser publicadas, tanto no Brasil como em Portugal, mas ainda de forma tímida e esparsa.

A seleção das obras-síntese se deu com base em critérios delineados por pesquisa prévia, com levantamento da produção de cada país, por década, mediante registro em relatórios bibliográficos detalhados. Para ser incluída na categoria de obra-síntese, levaram-se em conta a abrangência da pesquisa, o período histórico compreendido e a consistência teórica e analítica.

\footnotetext{
${ }^{1} \mathrm{O}$ corpus da pesquisa é composto pelos seguintes estudos: I - Brasil: (1) Dencker; Kunsch (1996); (2) Oliveira (1991); (3) Costa (2006); (4) Motta (2006); Trigueiro (2005); II - Portugal: (6) Schmidt (2003); (7) Garcia (2004); (8) Pereira Rosa (2006); (9) Vieira (2006); (10) Freitas (2007).
} 
Outro critério considerado foi o reconhecimento e a legitimidade desses estudos pela comunidade acadêmica no Brasil e em Portugal, a partir do levantamento das obras mais citadas em comunicações apresentadas em congressos científicos, artigos de periódicos, capítulos de livros e demais publicações relacionadas ao tema no período compreendido pela pesquisa. ${ }^{2}$

Cabe ressaltar que a análise não se limitou a essas dez obras selecionadas. Esse corpus constitui a referência principal, o que não significa a exclusão de outras obras. De forma complementar, foram utilizadas dezenas de publicações adicionais, com o intuito de complementar as informações e enriquecer o estudo. O material complementar ao corpus principal é composto por textos de periódicos, de portais acadêmicos, comunicações científicas apresentadas em eventos, além de livros e capítulos de livros que apresentam temáticas relacionadas ao tema analisado. Em alguns casos, foram referenciados estudos nos quais o tema jornalismo de ambiente não aparecia em primeiro plano. Entretanto, a leitura revelava dados e informações de interesse para a contextualização da pesquisa ou para a complementação de explicações expostas nas obras que compunham o corpus de análise ${ }^{3}$.

\section{A Perspectiva Sociopolítica das Fontes de Informação}

O estudo das fontes de informação se reveste de especial importância na sociologia dos emissores, área que estuda o processo de produção da informação jornalística (newsmaking). Nessa perspectiva de estudos, as pessoas e instituições que fornecem dados, informações e declarações são encaradas como emissores, chegando a exercer, algumas vezes, maior importância do que os próprios jornalistas, visto que esses dependem de bons informantes

\footnotetext{
${ }^{2} \mathrm{O}$ reconhecimento e a legitimidade das pesquisas sobre jornalismo ambiental foram avaliados em cinco etapas: (1) Levantamento das obras mais citadas em congressos científicos, artigos de periódicos, livros e demais publicações afins. (2) Indicação espontânea de estudos e investigações e publicações sobre o assunto - essa indicação foi solicitada por meio de contatos informais, como e-mails, telefonemas e abordagens diretas nos eventos acadêmicos. (3) Seleção provisória - realizada com base em todos os critérios anteriores, levando-se em conta ainda a chancela de instituições científicas, agências e associações de pesquisa da área de Comunicação.

(5) Seleção final - escolha definitiva das 10 obras para a composição da amostra.

${ }^{3}$ A lista das obras complementares consta nas referências.
} 
para publicarem notícias que lhes conferem reconhecimento e prestígio. As fontes são um fator determinante para a qualidade da informação produzida pelos mass media. No entanto, a mitologia profissional "tende, pelo contrário, a realçar o papel ativo do jornalista, marginalizando o contributo, em muitos aspectos essencial, das fontes" (WOLF, 1995; p.199).

As fontes oficiais e institucionais ocupam um lugar central no processo de produção de informações jornalísticas atualmente, pois correspondem melhor do que as outras às necessidades organizativas das redações. Isso decorre da regularidade das relações entre jornalistas e representantes de órgãos públicos, o que, pela frequência dos contatos, permite que se estabeleça uma relação de confiança. Mas, vale ressaltar, que isso só se aplica mais facilmente aos jornalistas especializados, ou seja, aqueles que atuam por muito tempo em uma mesma área, como política e economia, por exemplo.

A razão principal pela qual os jornalistas recorrem, repetidas vezes, a um número restrito de informantes oficiais e institucionais se deve ao fato de que a reciprocidade da relação faz criar um modelo cumulativo. Esse modelo permite a veiculação de temas já amplamente difundidos e socialmente aceitos, o que é essencial às necessidades produtivas e aos procedimentos organizativos do trabalho jornalístico. A credibilidade de representantes de órgãos oficiais e institucionais decorre da própria rotina e organização do trabalho dos jornalistas, os quais "preferem fazer referência a fontes oficiais ou que ocupam posições institucionais de autoridade" (WOLF, 1995; p.202).

A exceção, no uso de informações oficiais / institucionais pela imprensa, ocorre com a produção de informações sobre temas especiais, a exemplo dos cadernos e suplementos temáticos. Nesse caso, a escassez de tempo não é tão imperiosa, uma vez que, geralmente, a equipe de produção dispõe de dias ou semanas para elaborar o produto final. Por isso, são mais utilizadas as fontes alternativas e individuais, até pelo tom testemunhal, ilustrativo ou mesmo pela construção de personagens, um processo similar ao da ficção, que cada vez mais a mídia utiliza atualmente, como lembra o autor mencionado. Nessa situação específica, o ineditismo dos informantes constitui um dos critérios de noticiabilidade e um valor-notícia, ou seja, torna-se um critério de valorização da informação - ou pelo menos de sua forma de apresentação, segundo a teoria do newsmaking (WOLF, 1995), que ressalta as rotinas e dinâmicas de produção do jornalismo, enfatizando sua dimensão de racionalidade técnica e pericial.

De uma perspectiva teórica mais ampla, é possível fazer um paralelo entre o newsmaking e os sistemas peritos gerados pela modernidade, 
estudados sob a ótica da sociologia weberiana, que considera sistemas de informação e aparelhos culturais como resultantes do processo histórico de racionalização das civilizações ocidentais (WEBER, 1999). Na esteira do argumento weberiano, é cabível a discussão do conceito de sistemas peritos como decorrentes da modernização (GIDDENS, 1991), o que implica o avanço do conhecimento técnico e tecnológico, fruto da racionalização e da especialização técnica, que geram expertise, que se reveste de capital simbólico, o que se aplica diretamente ao jornalismo. De forma resumida, os sistemas peritos podem ser entendidos como sistemas desenvolvidos por especialistas com aplicação na sociedade e repercussão direta nas relações sociais e culturais. Como explica Giddens, a confiança é a chave do relacionamento entre o indivíduo e esses sistemas peritos, ou seja, o usuário confia em seu funcionamento e em sua eficácia técnica, embora não entenda os mecanismos operacionais que possibilitam seu funcionamento. A expertise é requerida apenas da parte de quem fornece os serviços ou produtos resultantes dos sistemas peritos. Sob essa perspectiva, um serviço de informação é entendido como sistema perito, seja um banco de dados ou um jornal. A expertise técnica e a perícia profissional são exigidas formalmente dos profissionais de informação, mas não do usuário. Assim como o paciente confia no cirurgião, o leitor confia no funcionamento do sistema de informação, o que lhe confere credibilidade (MIGUEL, 1999).

\section{Jornalismo, Ambiente e Fontes - Análise Qualitativa}

As investigações analisadas mostram que as fontes oficiais são predominantes na cobertura de imprensa sobre ambiente no Brasil e em Portugal, especialmente na década de $1970^{4}$, quando o noticiário, mesmo pouco diversificado, registrava cerca de 90 a $95 \%$ de informações fornecidas por fontes governamentais, ou seja, quase monopólio (BARROS, 1999). Nas décadas seguintes, as alternativas foram sendo ampliadas, e as instituições oficiais passaram a representar em média de $50 \%$ a $60 \%$ nas citações das amostragens do noticiário nas décadas de 1980 e início de 1990 (BARROS,

\footnotetext{
${ }^{4}$ Mesmo fora do escopo temporal da análise, esses dados são relevantes, a título de ilustração.
} 
2004). Os serviços públicos são os principais fornecedores de informações para a imprensa, no que diz respeito à ecologia. A diferença está apenas na abrangência, ou seja, os órgãos governamentais da esfera federal são os que mais se constituem fontes de informação ambiental, em torno de $70 \%$ das citações no âmbito das fontes oficiais em cada período mencionado (BARROS, 2004).

Os estudos ecológicos decorrentes de informações oriundas de entidades científicas também reforçam a intervenção das fontes oficiais, uma vez que, em sua maioria, são provenientes de pesquisas realizadas por universidades ou institutos de pesquisas ligados a autarquias públicas. Esse enfoque também é comum nas investigações brasileiras e portuguesas. Isso implica uma visão inicial de que o discurso científico sobre meio ambiente não constituía uma fonte autônoma, mas uma variação das fontes oficiais, uma vez que os pesquisadores vinculados a instituições públicas, especialmente as federais, se manifestavam em nome do Estado brasileiro ou do próprio Governo. Até porque a política científica era inteiramente depende do Estado (MOREL, 1979). Com o passar do tempo é que passou a se desenvolver a formação de uma comunidade científica minimamente independente (SCHWARTZMAN, 1979; FERNANDES, 1990).

No Brasil, o uso constante de fontes institucionais externas também contribuiu para a chamada globalização da agenda ecológica. Trata-se dos documentos oficiais produzidos por organismos internacionais multilaterais, os quais se enquadram na categoria de fontes oficiais. Mesmo não sendo governamentais no sentido estrito do termo, tais instituições representam interesses alinhados à política externa dos países centrais, com algumas exceções, ou funcionam como agências de promoção dos interesses dos estados e governos que financiam suas atividades, na maioria dos casos ou em determinadas situações. Além disso, muitos dos dirigentes desses organismos são indicados direta ou indiretamente pelos governos dos países que exercem comando na agenda internacional referente às atribuições da instituição multilateral (WOLF, 1995). Da mesma forma que o discurso oficial, o qual se mantém mais sintonizado com os temas globais, preocupando-se mais com a opinião pública internacional, a imprensa brasileira seleciona e destaca as informações concernentes à agenda externa, com o respaldo de documentos ou fontes institucionais. Essa tendência é mais intensa em assuntos como Amazônia, aquecimento global, chuva ácida e clima (TRIGUEIRO, 2005). $\mathrm{Na}$ cobertura sobre os temas ligados à Amazônia, por exemplo, o que mais se lê nos jornais e revistas são reportagens que destacam as opiniões 
de entidades, autoridades, personalidades, cientistas e grupos estrangeiros sobre a região. A pauta parece que é definida de acordo com a repercussão externa (MELLO, 2003). As fontes e os documentos são selecionados em consonância com os pressupostos dessa pauta, analisam os autores citados.

Entre as fontes internacionais mencionadas com mais frequência nas pesquisas, destacam-se: organismos internacionais, como ONU, Unesco e Organização Meteorológica Mundial; entidades governamentais, como NASA, FMI, e universidades estrangeiras, sobretudo norte-americanas, além dos relatórios do Banco Mundial, os chamados World Development Report. Em relação às fontes internacionais, é oportuno destacar outra característica em comum nos estudos comparados: o uso recorrente de fontes documentais. Praticamente a totalidade das pesquisas realizadas, tanto no Brasil como em Portugal, mencionam dados dos principais documentos sobre meio ambiente, sobretudo aqueles produzidos pela Organização das Nações Unidas (ONU), pelo Clube de Roma e pelo Banco Mundial. Dentre esses documentos, destacam-se os relatórios anuais do Programa das Nações Unidas para o Meio Ambiente (PNUMA), os relatórios periódicos do Banco Mundial, tais como: (a) World Development Report, 1990; (b) World Military Expedenditures, 1990; (c) Development and Environment: World Development Report, 1990); (d) World Development Indicators, 1990.

Entre os demais documentos mencionados com frequência estão: (1) Habitat: Estratégia mundial de vivenda hasta El año 2000 (NAIRÓBI, 1990); (2) Fome: O desafio dos anos de 1990 (SÃO PAULO, 1990) - relatório do Fundo das Nações Unidas para a Alimentação e a Agricultura; (3) Qualidade de Vida, 1992: Salve o Planeta (1992) - relatório do Worldwatch Institute, (4) e o relatório da Agência Europeia do Ambiente Os recursos hídricos da Europa: uma avaliação baseada em indicadores (LUXEMBURGO, SERVIÇO DAS PUBLICAÇÕES OFICIAIS DA UNIÃO EUROPEIA, 2003).

O relatório da Comissão Mundial sobre Meio Ambiente e Desenvolvimento das Nações Unidas, Nosso Futuro Comum, publicado em 1988, é o documento oficial mais citado pelos estudos analisados, ao lado da Declaração de Estocolmo, da Declaração da Cúpula da Terra, a Agenda 21, a Convenção para Mudanças do Clima e o Protocolo de Kyoto. O uso dessas publicações consiste praticamente como fonte de dados estatísticos e análises sobre cenários e perspectivas ambientais.

Além dos documentos produzidos com a chancela de organismos internacionais, os estudos realizados no Brasil utilizam largamente relatórios e dados oficiais das instituições públicas nacionais. Assim, a cobertura da 
imprensa reforça o poder do discurso oficial, o qual está sempre se justificando diante da comunidade internacional e destacando as belezas naturais e o potencial de recursos hídricos, de fauna e flora da Amazônia brasileira. Em Portugal, como destacam Schmidt (2003); Pereira Rosa (2006); Vieira (2006) e Garcia (2004), a agenda ambiental a partir da cobertura dos media passou a ser diretamente influenciada pelos problemas ecológicos de ampla repercussão na Europa, especialmente no período de 1940 a 1980. Entre os temas da agenda europeia que repercutiram na cobertura jornalística de Portugal, destacam-se os riscos da expansão do uso dos pesticidas na agricultura, os investimentos em projetos nucleares, o acidente de Chernobyl e as tentativas políticas de implantação de medidas ambientais conjuntas. No plano nacional, os autores destacam a contestação ao cultivo intensivo de eucaliptos para a produção de papel e celulose e a discussão sobre os riscos de extinção de espécies da fauna portuguesa, como a cegonha branca; além da poluição das praias, o impacto ambiental de grandes obras, como a Ponte 25 de Abril, e a proteção dos mananciais e de lugares como a Serra da Arrábida e o Parque do Gerês.

Outro aspecto comum aos estudos realizados nos dois países é a discussão sobre a legitimação das fontes oficiais. Tanto as revistas como os jornais e as emissoras de televisão exercem uma função de reconhecimento dessas fontes no que se refere ao noticiário sobre meio ambiente no Brasil e em Portugal. Essa função, indiretamente, pode ser considerada mecanismo de reforço do discurso oficial, uma vez que as "falas competentes" que adquirem visibilidade na cobertura jornalística são, em sua maioria, de titulares de cargos da alta burocracia governamental, o que reforça o poder do Estado no que tange à formulação do discurso sobre meio ambiente.

Com base nos estudos analisados, as características gerais mais marcantes do discurso ecológico produzido no âmbito governamental tanto no Brasil como em Portugal podem ser assim resumidas, conforme fazem Barros e Sousa $(2010)^{5}$ :

\footnotetext{
${ }^{5}$ Um dos princípios da metanálise, técnica de pesquisa adotada para o presente estudo, é a fidelidade às categorias analíticas dos estudos analisados. Por essa razão, optamos pela manutenção dos tópicos citados pelos autores estudados nos três segmentos: discurso oficial, científico e ecológico.
} 
1. Caráter defensivo - caracteriza-se, principalmente, pela natureza dos argumentos, os quais assumem a conotação de resposta às pressões internacionais. Grande parte dos discursos consiste em apresentar uma defesa do governo em face das críticas externas.

2. Redundância - a redundância se confirma pela reedição sistemática dos argumentos centrais, como a defesa da soberania nacional e do direito de livre utilização dos recursos naturais do País, por exemplo, especialmente no caso do Brasil.

3. Simplificação - consiste em uma estratégia dos órgãos oficiais para fixar suas ideias, mediante a simplificação das que são apresentadas.

4. Ufanismo - manifesta-se na incessante exaltação dos atributos naturais do País, sobretudo nos discursos de autoridades brasileiras sobre as belezas naturais, embora essa característica também seja compartilhada pelas manifestações do governo português, embora em menor proporção.

5. Secundarização - o que denominamos secundarização é, na realidade, a tendência do discurso governamental para a marginalização da ecologia em si, a qual sempre aparece atrelada a aspectos periféricos dos problemas ecológico-ambientais e raramente como fator central. É o que ocorre, por exemplo, nos textos que ressaltam a importância da economia, do desenvolvimento, da qualidade de vida, enfim, de quase todas as categorias principais.

6. Circunstancialidade - manifesta-se em muitos momentos também, sendo o exemplo maior os discursos que antecederam a Cimeira da Terra (ECO, 92). Mas essa característica também aparece em outros momentos como estratégia oficial para amenizar o impacto dos problemas denunciados pela imprensa ou pelas entidades ambientalistas.

7. Generalidade e superficialidade - é comum, nos dois países, o governo abordar os assuntos da agenda ecológica de modo genérico e superficial, utilizando-se de expressões vagas como desenvolvimento, preservação ecológica, interesse comum, qualidade de vida, etc.

Em termos gerais, o que se pode deduzir do posicionamento oficial sobre meio ambiente no Brasil e em Portugal é que se trata de um discurso 
genérico, fragmentado e pouco sistematizado. Tais características refletem os atributos da frágil política ambiental no período e, mais especificamente, da inexistência de uma política ambiental no sentido estrito nos dois países, como ressaltam Caribé (1988; 1992), Vieira (1995; 1992), SoromenhoMarques (2001), Schmidt (2003) e Pereira Rosa (2006). Caribé (1988) ressalta que, além de serem recentes os mecanismos de proteção à natureza, existe ainda o problema da falta de continuidade dos projetos e filosofias das instituições. A autora analisa o caso específico do Brasil, mas a constatação também se aplica ao caso português.

No Brasil, somente a partir do Governo Sarney (1985-1989) é que houve uma tentativa de se delinearem alguns parâmetros para a definição de política ambiental no País, com o primeiro grande plano governamental voltado para a questão: o Programa Nacional de Meio Ambiente (PNMA), popularmente conhecido como "Programa Nossa Natureza". Voltado basicamente para a gestão ambiental, esse programa priorizou o desenvolvimento institucional do Instituto Brasileiro de Recursos Naturais Renováveis (IBAMA), destacando-se a informatização do órgão, a capacitação de recursos humanos e o desenvolvimento de tecnologias para o estudo e preservação de biomas específicos como Amazônia, Pantanal e Cerrados.

No caso de Portugal, os analistas atribuem ao governo de Mário Soares (1986-1996) a primeira tentativa de formulação de um conceito de política nacional de ambiente. Portanto, nos dois casos, as políticas foram marcadas por medidas pontuais, corretivas e remediadoras. Em outras palavras, ações voltadas para atenuar, diante da opinião pública nacional e internacional, os efeitos da degradação ambiental. Outra constatação é a de que o discurso ecológico apresentado pelo Estado (nos dois países) é fruto de um consenso induzido, ou seja, é resultado de um jogo desigual de poderes.

Nessa ordem de ideias, o direito moderno tornou-se mecanismo imprescindível para a atuação dos Estados empreendedores, no que concerne à construção social da representação da natureza, o que se tornou mais nítido, principalmente, com a emergência do Direito Ambiental como ramo do Direito Público e como variação e ampliação das fontes oficiais para o jornalismo ambiental. Tanto no Brasil como em Portugal, essa tendência é evidente, desde a criação das primeiras leis voltadas para a questão, a partir das décadas de 1970 e 80. Com isso, o direito ambiental passou a ocupar "posição de destaque no processo de introjeção social da 'fisionomia' da natureza em termos adequados à questão ambiental" (FUKS,1992; p.123).

Essa novidade jurídica oportunizou a elaboração de um conjunto de 
representações e pressupostos, por parte do Estado, cujos fundamentos são um conceito de natureza e um entendimento do que seja o homem, tendo como pressuposto a relação entre ambos. A natureza deixa de ser a presa para se tornar vítima, objeto da predação humana. A autoimagem do homem não é mais aquela do início dos tempos modernos, quando a exaltação à dignidade humana era combinada com um ingênuo sentimento de otimismo quanto aos resultados do uso de poderes que descobria em si próprio. Agora, o homem começa a adquirir consciência de uma crise surgida como consequência direta das atividades antrópicas, o que abala a sua confiança em ser o dono do meio ambiente. Por outro lado, como destaca Schmidt (2003), essa mudança de percepção foi crucial para a politização do debate ambiental, pois o foco se desloca das causas naturais para as ações humanas e suas consequências sobre o ambiente. Essa mudança de mentalidade contribuiu, inclusive, para o surgimento de diretrizes jurídicas, o que confirma o potencial de intervenção desse tipo de fonte de informação no jornalismo ambiental.

\section{Fontes cientificas}

As fontes científicas são reconhecidas pelos pesquisadores como relevantes para a constituição da agenda ambiental e como provedoras de informação para a imprensa nos dois países (FERNANDES, 1990; SCHMIDT, 1993). De forma mais específica, no Brasil, essa questão perpassa todos os estudos publicados na coletânea Meio Ambiente no Século XXI, organizado por Trigueiro (2005). São 21 capítulos, cada um sobre um tema específico, com destaque para as áreas de educação ambiental, energia, agricultura, ciência e tecnologia, política e opinião pública. A amplitude dos temas revela a concepção da obra de chamar atenção para a transversalidade das questões ambientais, que permeiam praticamente todas as áreas de conhecimento atualmente.

O assunto também é discutido por Andrade (2004), que estudou especificamente a evolução das abordagens científicas sobre meio ambiente no telejornalismo e concluiu que as matérias sobre ecologia surgiram nos espaços para divulgação científica de forma tímida, pontual e sensacionalista até se projetarem com grande ênfase e exigirem o posicionamento de especialistas das mais diversas áreas científicas.

Em Portugal, o livro de Schmidt (2003) apresenta argumento similar, decorrente da análise da evolução das abordagens científicas do ambiente 
na programação da Rádio e Televisão Portuguesa (RTP). Na década de 1970, por exemplo, destaca a autora, os especialistas procurados pelos jornalistas se limitavam aos investigadores de áreas como Botânica, Zoologia e Agronomia. A partir da década de 1980, o leque de áreas acadêmicas começou a ser expandido e hoje está tão abrangente e transversal quanto no Brasil. Pereira Rosa (2006) também dedica partes específicas de sua obra à análise da relação entre jornalistas e cientistas do ambiente. Neste quesito, o autor destaca um certo tipo de aliança do jornalismo com áreas especializadas de ambiente, como Engenharia Florestal, Biologia, Botânica, Química e Física. O pesquisador atribui a essa aliança o crescente interesse da população pela atividade dos cientistas:

O crescente interesse da população pela actividade dos cientistas, expressa, por exemplo, na eclosão vertiginosa de publicações dedicadas à divulgação científica e na abertura de novas secções sobre o tema nos jornais generalistas, motivou uma modificação gradual de comportamentos e uma relativa abertura dos cientistas à divulgação (PEREIRA ROSA, 2006; p.47).

Com a ampliação da divulgação de pesquisas e análises científicas sobre os mais variados aspectos relacionados aos temas ambientais, o interesse do público tende a crescer ainda mais. Um exemplo dessa tendência é a divulgação dos estudos relativos às mudanças climáticas, por meio de grandes reportagens, documentários e programas televisivos sobre história do clima, métodos para a análise de geleiras e glaciares, o desenvolvimento de tecnologias para aferir o nível de emissão de gases de efeito estufa e outros estudos de igual impacto, como mudanças no regime de chuvas e as causas do aquecimento global.

Essa abertura da agenda ambiental e a conexão direta com o cotidiano dos usuários de informação da mídia contribuíram para diminuir as resistências dos cientistas em relação à divulgação da mídia. Como explicam Targino e Barros (1994), na lógica da comunidade científica anterior à consolidação sociocultural do fenômeno da mediatização, os cientistas percebiam a divulgação da mídia com ressalvas, por se tratar de um sistema distinto das regras do campo científico (BOURDIEU, 1983). Entretanto, como observa Caldas (2004), a mediatização aproximou os dois campos e favoreceu parcerias entre cientistas e jornalistas na divulgação científica e ambiental.

Do ponto de vista da relação anterior entre cientistas e jornalistas, ou seja, no contexto da resistência e desconfiança dos primeiros, o estudo de Amaral (1986) aponta quatro fatores que contribuem para reforçar a resistência 
dos media em relação à divulgação de temas de natureza científica, os quais também se aplicam ao estudo da relação entre jornalistas e cientistas do ambiente:

- Desinteresse dos newsmakers - ainda existe o predomínio da ideia de editores e gestores de notícias de que temas científicos não interessam ao grande público e que esse suposto desinteresse compromete a Audiência e afasta anunciantes.

- Retraimento das fontes científicas - os investigadores renomados e os gestores públicos de universidades e institutos de pesquisa ainda tendem a se retrair e evitar contato mais frequente com a imprensa, resultado de uma longa tradição de distanciamento entre cientistas e leigos (os jornalistas são considerados leigos pelos especialistas).

- Desconfiança do cientista em relação ao jornalista - as fontes especializadas - por preconceito ou precaução - evitam passar todas as informações para os jornalistas, geralmente por desconfiança. Para os cientistas, os jornalistas simplificam excessivamente as informações, por falta de capacidade para compreender os dados de pesquisas.

- Linguagem técnica-os temas científicos tratados em linguagem técnica não atraem o público, o que compromete maiores investimentos dos media na cobertura de temas especializados.

Garcia (2004) apresenta subsídios para quem escreve sobre ambiente, do ponto de vista de disseminação de informações técnicas para públicos leigos. Com isso, o autor sugere que se trata de uma forma de divulgação científica. A respeito dessa abordagem existem algumas divergências quanto à concepção de jornalismo de divulgação científica. Para Santos (1989), divulgação científica é o processo pelo qual se transmitem informações científicas ao grande público, de forma acessível. Bueno (1985) critica tal concepção, porque, a seu ver, reduz o processo de divulgação científica via jornalismo a uma prática de transferência de informação, ou seja, legitima o jornalismo como atividade unilateral, transferindo a outrem um determinado saber.

\section{As fontes não governamentais}

Do ponto de vista histórico, depois das fontes oficiais e da comunidade científica, as organizações não governamentais também são reconhecidas como fontes fundadoras e fundamentais do ponto de vista da redefinição da 
noticiabilidade no campo ambiental (BARROS, 1996; SCHERER-WARREN, 1996; BORN, 2005; PEREIRA ROSA, 2006). Esse é um dos eixos importantes das pesquisas realizadas nos dois países. Os autores citados põem em relevo o papel das organizações ambientais do ambiente, sobretudo os efeitos da atuação delas sobre a produção jornalística. O crescimento da importância de movimentos cívicos "em representatividade e peso negocial nas sociedades contemporâneas modificou os relatos jornalísticos e promoveu a ascensão de fontes que a sociologia do jornalismo até então ignorara”. (PEREIRA ROSA, 2006, p.8).

As ONGs surgiram nos dois países como movimentos marginais, com o objetivo de contestar as iniciativas oficiais e criticar a falta de políticas para a preservação ambiental (PÁDUA, 1986; SOROMENHO-MARQUES, 1996). Enquanto atuavam movidos pelas convicções ideológicas radicais, a imprensa destinava pouco espaço às suas atividades, e seus representantes não gozavam de prestígio e credibilidade como fontes de informação. A média, segundo registros quantitativos da década de 1970 ao início de 1980, ficava abaixo de 3\% no Brasil e menos de 2\% em Portugal (BARROS; SOUSA, 2010). Contudo, após a Conferência do Rio em 1992, as ONGs conquistaram a confiança dos jornalistas e passaram a atuar como fontes credíveis e de prestígio, resultado da profissionalização dos movimentos e de um planejamento estratégico voltado para atrair a atenção da mídia, um processo que seguiu uma tendência internacional. Conforme Lycarião (2010; 2011), os grandes eventos internacionais e a atuação global de instituições ambientais, a exemplo do Greenpeace, contribuíram para acentuar a proximidade dessas entidades com a imprensa. Assim, tais entidades passaram a ocupar um papel mais expressivo na mediação jornalística na agenda ambiental, principalmente em assuntos de repercussão internacional, que envolvem questões técnicas e a tematização de riscos ecológicos. Essa análise sobre a atuação das Ongs ambientalistas internacionais é similar a argumentos apresentados em Portugal por Pereira Rosa (2006).

Ao analisar o caso da Quercus $^{6}$ em Portugal, Pereira Rosa (2006) recorreu a outros estudos realizados na Europa e nos Estados Unidos sobre

\footnotetext{
${ }^{6}$ Trata-se da Associação Nacional de Conservação da Natureza, a mais importante organização não governamental portuguesa do setor, que carrega o nome científico da árvore que é símbolo do país, o sobreiro (Quercus suber).
} 
as consequências da relação entre as organizações não governamentais do ambiente (ONGAS) e os media. A conclusão é que tanto as ONGAS interferiram no modo de se fazer jornalismo sobre ambiente, como elas próprias também foram afetadas por essa intervenção, sobretudo em decorrência das estratégias de aproximação dos jornalistas e adequação aos critérios de noticiabilidade e aos valores-notícia. As ONGAS, por sua vez, causaram impactos significativos no esquema convencional, que orientava a relação dos media com as fontes, até então, de natureza predominantemente oficiais. No modelo convencional, as instituições públicas funcionavam como “armazéns de notícias", sempre prontas a abastecer os jornalistas com dados, estatísticas e declarações.

A dificuldade inicial das entidades ambientalistas, conforme destaca Pereira Rosa, estava em romper o estereótipo de movimentos de contestação, sempre dispostos a disparar críticas contra os governantes e gerar polêmica, na maioria das vezes sem dados e informações de ordem objetiva. Assim, essas entidades eram procuradas pelos jornalistas apenas quando eles buscavam esse tipo de enquadramento. Essa relação esporádica e estigmatizada prejudicava os movimentos sociais, visto que sua imagem era associada geralmente a casos específicos, e suas declarações eram encaixadas em matérias jornalísticas já pré-formatadas, com o objetivo de acirrar os conflitos, numa perspectiva descontextualizada, que apontava, na maioria das vezes, para os comportamentos e fatos desviantes (PEREIRA ROSA, 2006).

As entidades ambientalistas passaram, então, a investir em estrutura, recursos e estratégias para modificar a relação com os media e com os jornalistas e, assim, conseguirem intervir na imagem delas projetada para a opinião pública. Nesse processo, as entidades ambientalistas passaram não só a fornecer informações em consonância com os pacotes mediáticos, mas também a exercer controle sobre a fase pós-cobertura, como estratégia de vigilância sobre os significados das notícias, visto que a divulgação delas produz efeitos imediatos na imagem da organização. Como explica o autor, as fontes preocupam-se em exercer controle sobre esse significado das notícias, "porque a publicação produzirá efeitos na organização a que estão vinculadas" (PEREIRA ROSA, 2006; p.39).

Essa estratégia é usada como meio preventivo, visto que os efeitos maléficos após a divulgação das notícias são praticamente irreversíveis, mesmo que haja direito de resposta. Assim, deduz-se que a visibilidade aos movimentos ambientalistas decorre de uma combinação de fatores. Além de 
atuarem em áreas de notória deficiência do Estado, as ONGAS passaram a ter domínio sobre o ciclo de produção das notícias e estabeleceram uma rede de relacionamento com os media, com a contração de serviços de jornalistas. Segundo Pereira Rosa (2006, p.74),

o conhecimento do ciclo noticioso, o relacionamento pessoal de alguns dirigentes com jornalistas, a capacidade de reagir rapidamente a um acontecimento e a facilidade de aceder a informação técnica e descodificá-la para a linguagem jornalística são os recursos que tornam os dirigentes de organizações não governamentais do ambiente fontes potenciais de informação. ${ }^{7}$

Além disso, as entidades tentam manter-se em evidência, ao alimentarem notícias, gerarem controvérsias e demandas para que seus aliados e oponentes também se pronunciem sobre os temas discutidos. Outra estratégia é a polarização com as instituições governamentais. Enquanto os representantes do Governo tentam fixar suas ações, numa perspectiva positiva, as entidades não governamentais ficam de plantão, prontas para apontarem lacunas em todas as ações governamentais (PEREIRA ROSA, 2006).

Born (2005) investiga especificamente esse ponto, no âmbito da realidade ambiental brasileira. Apesar dos estereótipos negativos em relação a essas entidades e da fragilidade institucional existente na maioria delas, as ONGAS "têm tido um papel cada vez maior e mais efetivo em políticas públicas e geração de iniciativas" (p. 107). Para o autor, a partir da perspectiva funcional, essas entidades passaram a exercer diferentes papéis na sociedade e na esfera política, os quais se complementam e reforçam seu poder de intervenção nas políticas públicas. As funções elencadas pelo estudioso são:

a) denúncia e revelação de fatos e problemas ambientais;

b) atuação em prol da educação ambiental e formação para a mobilização social;

c) assessoria jurídica para a promoção de direitos ambientais e a cobrança de atuação do Poder Público;

\footnotetext{
${ }^{7} \mathrm{O}$ autor chega a essa conclusão com base em entrevista com um dos dirigentes da Quercus, Francisco Ferreira.
} 
d) pesquisa e difusão do conhecimento ecológico;

e) monitoramento e fiscalização de obras públicas e empreendimentos que causam impacto ambiental;

f) implementação de projetos de sustentabilidade;

g) assessoria, disseminação e multiplicação de ideias e práticas ecologicamente sustentáveis;

h) formação de capital humano para atuar nas redes e projetos de sustentabilidade.

Em relação a Portugal, Soromenho-Marques (1996; 2001; 2005) publicou vários estudos que ressaltam o poder de intervenção política das organizações não governamentais do ambiente, especialmente a Quercus. Em entrevista a Pereira Rosa (2006, p.105), Soromenho-Marques declarou que a intervenção foi associada às estratégias dramáticas: "A ação dramática tem uma função essencialmente pedagógica. É uma metonímia, uma figura de estilo que visa concentrar o mundo num ponto para o qual se chama a atenção". Pereira Rosa, em seu estudo já citado anteriormente, reitera que, à medida que a Quercus se afirmava, como na discussão pública dos temas ambientais, também fortalecia a sua capacidade de influenciar a vida política.

Diante do exposto, com a análise das fontes oficiais, científicas e ecológicas, percebe-se a primazia das fontes oficiais nos estudos analisados, o que requer um breve registro. O que explica a predominância das fontes oficiais perante as fontes científicas e aquelas que representam as próprias entidades ambientais? Como analisam Barros e Sousa (2010), os estudos sobre meio ambiente e jornalismo retratam as práticas e os modos do fazer jornalístico dos dois países. Isso implica a constatação de que, no período analisado, a imprensa conferiu maior destaque às fontes oficiais. Por que isso ocorreu?

Ao apontarem argumentos acionados do campo da sociologia do jornalismo, mais especificamente da chamada sociologia dos emissores (WOLF, 1995; BARROS, 2015b), os autores chamam atenção para a complexa relação entre Estado e imprensa nos dois países, com ênfase para a força das instituições governamentais como fontes de informação para jornalistas. Barros e Sousa (2010) explicam ainda que os cientistas durante muito tempo hesitaram em fornecer informações para a imprensa, mediante a justificativa de que a arena midiática seria um espaço de sensacionalismo, simplificação 
e generalização, o que dificultaria a exposição adequada de argumentos científicos.

Já os movimentos ecológicos foram vistos de forma estigmatizada pela imprensa durante muito tempo, como atores outsiders, segundo apontam os referidos autores. Levou muito tempo para que as entidades ecológicas fossem consideradas fontes credíveis, complementa Pereira Rosa (2006). Os órgãos e atores do Estado, ao contrário, sempre tiveram interesse em pautar e agendar a imprensa, inclusive no que se refere à agenda ambiental, como estratégia de divulgar os temas e perspectivas de interesse governamental. Isso explica a estreita relação dos jornalistas com as fontes oficiais, o que se justifica ainda pelas estruturas de informação disponíveis para gerenciar a relação entre o Estado e a mídia, como as assessorias de imprensa das instituições estatais, além do relativo acesso aos documentos oficiais e às autoridades públicas, por meio de entrevistas, declarações e comunicados, conforme explicam Barros e Sousa (2010).

\section{Comentários Finais}

Após a análise proposta, o que se observa é que os estudos de jornalismo realizados no Brasil e em Portugal, do ponto de vista histórico, identificam e tematizam as fontes de informação que mais exerceram influência qualitativa sobre o jornalismo ambiental, com visível predomínio das fontes oficiais/governamentais, seguidas de fontes científicas e de organizações não governamentais. À luz do que foi apresentado anteriormente sobre a importância das fontes, no âmbito da sociologia dos emissores, tentaremos aprofundar, agora, as razões específicas que justificam a constatação apontada, iniciando pela atuação do Estado.

Em ambos os países, exerceu papel reativo, na esteira da divulgação científica, da intervenção das entidades ambientalistas, e da atuação de partidos políticos calcados na ideologia conservacionista (SOROMENHOMARQUES, 2001). A polarização entre essas vertentes e o discurso oficial foi própria das primeiras fases do ambientalismo nos dois países, marcado pela dicotomia entre os diagnósticos e prognósticos negativos da comunidade científica e pelos pronunciamentos do Estado voltados para a produção do consenso. O discurso oficial, durante os períodos iniciais de emergência do ambientalismo, principalmente na década de 1970, era reforçado pelas instituições científicas governamentais dos dois países; mas, com 
a consolidação de uma comunidade científica com maior autonomia, as pesquisas científicas passaram a interpretar os fatos ecológicos de forma crítica e independente, especialmente no caso das ciências sociais (VIEIRA, 1992; SCHMIDT, 1993).

Sob a perspectiva das fontes científicas, destaca-se seu papel socioeducativo, para a difusão e a popularização do conhecimento científico produzido pelos mais diversos campos de saber, em que é cada vez maior a proliferação de informação deles oriunda. Autores como Melo (1982), além dos já mencionados, ressaltam que a disseminação de informações científicas não deve se restringir à mera divulgação de fatos e dados. Seu papel deve ser mais abrangente, ou seja, sua atuação deve se pautar pela dimensão didática, que favoreça a compreensão do tema exposto, a fim de motivar mudanças comportamentais dos indivíduos, evitando a superficialidade e a tendência para difundir dados e informações sem criteriosa apuração.

A consolidação de fontes independentes, a partir da década de 1980, é apontada como marco na agenda ambiental em Portugal (PEREIRA ROSA, 2006) e no Brasil (BARROS, 1996). Entretanto, os autores concluem que o êxito das organizações não governamentais se justifica por uma mudança de posição: as entidades deixaram de ser apenas promotoras de protestos para se tornarem referências em diagnósticos especializados, capazes de apresentar análises técnicas confiáveis sobre os temas em discussão pela agenda governamental e pela comunidade científica. Assim, essas organizações tornaram-se fontes peritas de alta credibilidade. Além disso, essas entidades modelaram suas estratégias para formatar suas mensagens de modo a atrair a atenção dos media. Ao superarem as concepções radicais do ambiente, essas instituições passaram a investir na constituição de redes para fortalecer o trabalho integrado e diversificar as estratégias de intervenção nas políticas públicas de defesa dos recursos naturais e de promoção da sustentabilidade.

Além disso, tais organizações desenvolveram amplo potencial para ações políticas e de intervenção crítica em relação ao planejamento, execução e avaliação de políticas públicas. Tanto no Brasil como em Portugal existem estudos que destacam esse potencial de intervenção, apontado como responsável pelo novo desenho de ações políticas voltadas para o campo ambiental. A intervenção de tais entidades levou as instituições oficiais a adotarem procedimentos e metodologias mais transparentes, em função da cobrança e da vigilância permanente das instituições do Terceiro Setor.

Em suma, o que se pode concluir é que as três vertentes de fontes de informação analisadas seguiram a mesma lógica de racionalização dos 
sistemas peritos típicos da modernidade, cada uma a seu modo. Sob essa perspectiva, os três segmentos de fontes aqui analisados seguiram essa tendência. O Estado procurou investir em sistemas peritos de informação e de profissionalização técnica das assessorias de imprensa para a gestão do relacionamento com a mídia. Isso serviu para aperfeiçoar o principio da publicidade dos atos oficiais. A comunidade científica em si já constitui um sistema perito, com uma rede sociotécnica de produção e difusão de conhecimentos. Os cientistas são vistos pela mídia como atores peritos, detentores de um capital simbólico de grande valor para a credibilidade das informações divulgadas. As ONGs superaram o discurso dogmático e ideológico e passaram a adotar a lógica da racionalização pericial, com a profissionalização de seus agentes e a adequação às rotinas e dinâmicas de produção dos jornalistas, conforme foi analisado anteriormente.

Todas essas fontes se relacionam diretamente com o fenômeno sociocultural da mediatização, entendido como um processo social de referência. Nessa visão, os media funcionam como agenciadores de sentidos no mundo atual. Mesmo em se tratando de pensamento complexo e multifacetado - apesar do prisma específico de cada tipo de fonte -, o que dificulta uma análise crítica generalizante (MORIN, 1994), percebese a tendência para agregar representações sociais implicadas na lógica contemporânea da mediatização, ou seja, transmissão de ideias, valores e símbolos pelos meios de comunicação de massa e sua inserção nas relações sociais (PETITAT, 2011). Tal fenômeno foi intensificado com a adesão dos media à agenda ambiental a partir da década de 1990, com a repercussão da Cúpula da Terra (Rio 92) e a consolidação do ambientalismo como um fenômeno mediatizado, de acordo com os enquadramentos e as conveniências da agenda jornalística e dos debates e entrevistas.

Seria incoerente atribuir esse papel exclusivamente aos meios de comunicação, uma vez que vários outros atores e fontes contribuíram historicamente para elevar os temas ambientais ao status de visibilidade conquistado na atualidade. Assim, é necessário considerar a relevância histórica de vários segmentos que atuaram como atores peritos, tais como o Estado, a comunidade e as ONGs. Afinal, a ação histórica dessa constelação de agentes sociais também contribuiu para ampliar a cobertura dos media sobre a agenda verde. Em suma, podemos inferir que o somatório de todas essas forças é que concorreu para ampliar a repercussão dos temas ambientais nos media, em consonância com os pressupostos da teoria multifatorial da notícia (SOUSA, 2006) e os estudos sobre a historicidade dos fenômenos 
contemporâneos, na perspectiva da complexidade e da integração de saberes (MORIN 1994; LEFF, 2009).

\section{Referências}

AMARAL, Luiz.

(1986). “0 que é jornalismo científico". Revista de Comunicação Social, 16 (1-2); p.59-69.

ANDRADE, Lacy Varela Barca.

(2004). Iguarias na hora do jantar: o espaço da ciência no telejornalismo diário. Tese de Doutorado apresentada à Universidade Federal do Rio de Janeiro.

BARROS, Flavia Lessa de.

(1996). Ambientalismo, globalização e novos atores sociais. Sociedade e Estado, 21 (1); p.121-137.

BARROS, Antonio Teixeira de.

(2015a). 0 rural mediatizado: análise comparada Brasil-Portugal. Ambiente \& Sociedade, v. 18; p. 19-40.

(2015b). Sociologia da mídia: principais perspectivas e contrapontos. Século XXI: Revista de Ciências Sociais, v. 5, n.1; p.186223.

(2013). A visibilidade ambiental em perspectiva sociológica: estudo comparado BrasilPortugal. Sociologias, v. 15; p. 318-345.

(2004). As fontes no jornalismo ambiental no Brasil (1972-1992). Universitas, 2 (2); p.3954.

(1999). Atores e discursos ecológicos no Brasil: Estado, Ciência e Imprensa. Tese de Doutorado apresentada à Universidade de Brasília.

BARROS, Antonio Teixeira de; SOUSA, Jorge Pedro.

(2010). Jornalismo e ambiente: análise de investigações realizadas no Brasil e em Portugal. Porto: Edições Fernando Pessoa,
BORN, Rubens Harry.

(2005). Meio ambiente e terceiro setor. In: André Trigueiro (0rg.); Meio ambiente no século XXI. Campinas: Autores Associados.

BOURDIEU, Pierre.

(1983). 0 Campo científico. In: Renato Ortiz (Org.); Sociologia. São Paulo: Ática.

BRAGA, José Luiz.

(2006). Mediatização como processo interacional de referência. Texto apresentado no Grupo de Trabalho Comunicação e Sociabilidade, do XV Encontro Anual da Associação dos Programas de Pós-Graduação em Comunicação (Compós). Unesp/Bauru, São Paulo, junho de 2006.

BUENO, Wilson da Costa.

(1985). Jornalismo e ciência no Brasil: os compromissos de uma prática dependente. Revista Brasileira de Tecnologia, 16 (3); 21-25.

CALDAS, Maria das Graças. C.

(2004). Jornalistas e cientistas: a construção coletiva do conhecimento. Comunicação \& Sociedade, 41 (2).

CLARKE, Mark.

(2001). Formulating the problem. 0xford; University Press.

CARIBÉ, Rita de Cássia do Vale.

(1988). Informação ambiental no Brasil: subsídios para um sistema de informação. Dissertação de Mestrado apresentada à Universidade de Brasília.

COSTA, Luciana Miranda.

(2006). Comunicação e meio ambiente: análise das campanhas de prevenção a incêndios florestais na Amazônia. Belém: Núcleo de Altos Estudos Amazônicos. 
DENKER, Ada Freitas; KUNSCH, Margarida Maria Khrolling.

(1996). Comunicação e meio ambiente. São Paulo: Intercom.

FIGUEIRED0, Vilma.

(1996). Globalização, meio ambiente e novos atores sociais". Sociedade e Estado, 21 (1); 119-120.

FERNANDES, Ana Maria.

(1990). A Construção da Ciência no Brasil e a SBPC. Brasília, Editora da Universidade de Brasília.

FUKS, Mario.

(1992). Natureza e meio ambiente: a caminho da construção de um consenso social. In:Mirian Goldenberg (Org.); Ecologia, ciência e política. Rio de Janeiro, Renavan.

FREITAS, Helena de Sá.

(2007). Jornalismo de ambiente em Portugal: espécie em vias de extinção?. Jornal dos Jornalistas. Lisboa, janeiro-março.

GARCIA, Ricardo.

(2004). Sobre a Terra: um guia para quem lê e escreve sobre o ambiente. Lisboa: Público.

LEFF, Enrique.

(2009). Complexidade, racionalidade ambiental e diálogo de saberes. Educação \& Realidade, 34 (3); p.17-24.

LYCARIÃ0, Diógenes.

(2010). Greenpeace, espetáculo e internet: o intercruzamento entre diferentes modos de comunicação para a sustentação de debates na esfera pública. Tese de Doutorado apresentada à Universidade Federal de Minas Gerais.

LYCARIÃ0, Diógenes.

(2011). Internet e movimento ambientalista: estratégias do Greenpeace para a sustentação de debates na esfera pública. In: Rousiley Maia; Wilson Gomes; Francisco Marques (Org.); Internet e Participação Política no Brasil. Porto Alegre, Sulina.
LIMA, Venício Artur de.

(1993). Jornalismo oficial: a imprensa em Brasília. In: Jornalismo de Brasília: impressões e vivências. Brasília: Sindicato dos Jornalistas Profissionais do Distrito Federal.

MACULAN, Anne Marie.

(1995). A política brasileira de ciência e tecnologia. Novos Estudos CEBRAP, 43 (3); p.173-194.

MELLO, Neli Aparecida de.

(2003). Contradições territoriais: signos do modelo aplicado na Amazônia. Sociedade e Estado, 18.1-2; p.339-360.

MEL0, José.

(1982). Marques de. Impasses do jornalismo científico: notas para o debate. Comunicação \& Sociedade, 4 (7); p.19-24.

MIGUEL, Luis Felipe.

(1999). 0 jornalismo como sistema perito. Tempo Social, 11 (1); p.197-208.

MORIN, Edgar.

(1994). Introducción al pensamiento complejo. Barcelona: Gedisa.

MOTTA, Luiz Gonzaga; DRUMOND, José Augusto; QUEIROZ, Antônio Carlos, NASCIMENTO, Eliomar Pinheiro.

(2006). Os transgênicos e a grande imprensa: uma análise de conteúdo. In: Eliomar Pinheiro do Nascimento; João Nildo de Souza Vianna (Orgs); Economia, meio ambiente $e$ comunicação. Rio de Janeiro: Garamond.

MOREL, Regina.

(1979). Ciência e Estado: a política científica no Brasil. São Paulo: Queiroz.

PÁDUA, José Augusto.

(1986). Natureza e projeto nacional: as origens da ecologia política no Brasil. Rio de Janeiro: IUPERJ.

PEREIRA ROSA, Gonçalo.

(2006). A Quercus nas Notícias. Porto: Porto Editora. 
PETITAT, André.

(2011). Educação difusa e relação social. Educação \& Realidade, 36 (2); p.365-376.

SANTOS, Boaventura de Sousa.

(1989). Introdução a uma ciência pós-moderna. Rio de Janeiro: Graal.

SCHERRER-WARREN, Ilse.

(2003). Ambiente no Ecrã: Emissões e demissões no serviço público televisivo. Lisboa: Imprensa de Ciências Sociais.

SCHMIDT, Luisa.

(1996). Novos atores e práticas políticas ambientalistas na era da globalização. Sociedade e Estado, 21 (1); p.139-48.

(1993). O verde: preto no branco. Lisboa, Gradiva.

SCHWARTZMAN, Simon.

(1979). Formação da comunidade científica no Brasil. São Paulo: Ed. Nacional.

SOROMENHO-MARQUES, José Viriato.

(2001). Ambientalismo e política em Portugal: Valores e facetas de um arco-irís débil. In: Cristina Beckert (Coord.); Natureza $e$ ambiente: representações na cultura portuguesa. Lisboa: Centro de Filosofia da Universidade de Lisboa.

(2005). Estratégia nacional para o desenvolvimento sustentável: um projecto para Portugal. Lisboa, Pandora.

(1996). Ambiente e futuro: o caso português. Matosinhos, C.M. de Matosinhos.

SOUSA, Jorge Pedro.

(2006). Elementos de teoria e pesquisa da comunicação e dos media. Porto, Ediç̧̃es Universidade Fernando Pessoa.
(2000). As notícias e seus efeitos: as teorias do jornalismo e dos efeitos sociais dos medias jornalísticos. Coimbra, Minerva-Coimbra.

TARGINO, Maria das Graças; BARROS, Antônio Teixeira de.

(1994). Comunicação e ciência na ótica de pesquisadores brasileiros. Signo, 2 (2); P.1331.

TRIGUEIR0, André.

(2005). Meio ambiente na idade mídia". In: André Trigueiro (Coord.); Meio ambiente no século XXI. Campinas, Autores Associados.

VIEIRA, Paulo Freire.

(1995). Meio ambiente, desenvolvimento e planejamento. In: Eduardo Viola; Héctor Ricardo Leis; Use Sherer-Warren; et al. (Orgs.); Meio ambiente, desenvolvimento $e$ cidadania: desafios para as ciências sociais. São Paulo, Cortez.

(1992). A problemática ambiental e as ciências sociais no Brasil (1980-1990). In: HOGAN, Daniel Joseph Hogan; Paulo Freire Vieira (Org.); Dilemas sociambientais $e$ desenvolvimento sustentável. Campinas, Editora da Unicamp.

VIEIRA, Pedro Almeida.

(2006). Portugal: o vermelho e o negro. Lisboa, Dom Quixote.

WOLF, Mauro.

(1995). Teorias da comunicação. Lisboa: Presença.

\section{Recebido em}

março de 2014

Aprovado em

janeiro de 2016 